\title{
Improving Performance Improvement
}

\author{
Michael Hagen, MD
}

Since 2005, the American Board of Family Medicine (ABFM) has provided Diplomates with quality improvement tools for meeting the continuing certification Performance in Practice requirement. These tools took the form of Performance in Practice Modules (PPMs) based on the Deming model for quality improvement. ${ }^{1}$ The ABFM focused on common disorders frequently encountered by family physicians: diabetes, hypertension, asthma, depression, coronary artery disease, and heart failure. The ABFM also created a "comprehensive" PPM that provided diplomates with a broader set of measure options based on the Ambulatory Quality Alliance Starter Set. ${ }^{2}$ Since inception of the PPMs, Diplomates have completed $>98,000$ quality improvement activities (ABFM internal report, accessed February 20, 2017; available upon request.)

As Diplomates have gained experience and familiarity with quality improvement methodology, $\mathrm{ABFM}$ has received a growing number of requests for more flexible and varied options for meeting Performance in Practice requirements. In addition, with the development of the PRIME registry, ${ }^{3}$ ABFM needed a vehicle for accepting electronic clinical quality measures (eCQMs) for use in diplomates' performance improvement activities as well other reporting needs (eg, Physicians Quality Reporting System, Merit-Based Incentive Payment System $^{4}$ ). Briefly, the PRIME registry system includes several components: an extraction tool that derives data directly from electronic health records, a data warehouse in which to store these data, and the registry itself, which holds the eCQMs in order to support performance improvement and reporting.

Enter ABFM's revised Performance Improvement Activity (PIA) platform! Working with its vendor, FIGmd, ABFM has reworked the existing PPM product to support a broader spectrum of

Conflict of interest: The author is an employee of the ABFM. quality domains. In addition, instructional materials regarding quality improvement methods have been incorporated (another aspect of functionality requested by many diplomates over the years). We worked with consultants from Case Western Reserve University to develop these materials, and we have integrated them into the product to provide contextually appropriate guidance throughout.

The platform provides tools and resources for identifying performance gaps, developing and implementing quality improvement plans, and accomplishing the reporting needs described earlier. Although we designed the system to support direct population of quality data from PRIME, the system also supports manual data entry for those Diplomates who do not yet participate in the registry.

The PIA platform currently supports 49 eCQMs, as defined in the measures codes that the Center for Medicare \& Medicaid Services maintains for Physicians Quality Reporting System reporting. ${ }^{5}$ In addition, ABFM physician staff have identified and vetted (for validity and to remain free from commercial influence), for each measure, examples of web-based resources for implementing improvement plans. The platform organizes these resources by the categories included in the Chronic Care Model: clinical information systems, decision support, delivery system design, self-management support, and community resources and policies. ${ }^{6}$

Upon entering the system, Diplomates will see a dashboard that displays their performance on the 49 measures compared with that of their peers (Figure 1). They then select the measures for which they wish to create a performance improvement project, and develop an intervention plan using the Chronic Care Model-based resources provided (or custom actions that diplomates develop locally.) (Figure 2).

FIGmd and ABFM development staff anticipate deployment in the late second quarter or early third quarter of 2017.

In addition, $A B F M$ has contracted with collaborators at the University of Missouri-Columbia to create 
Figure 1. Screenshot displaying an example of available measures, showing the look and feel.

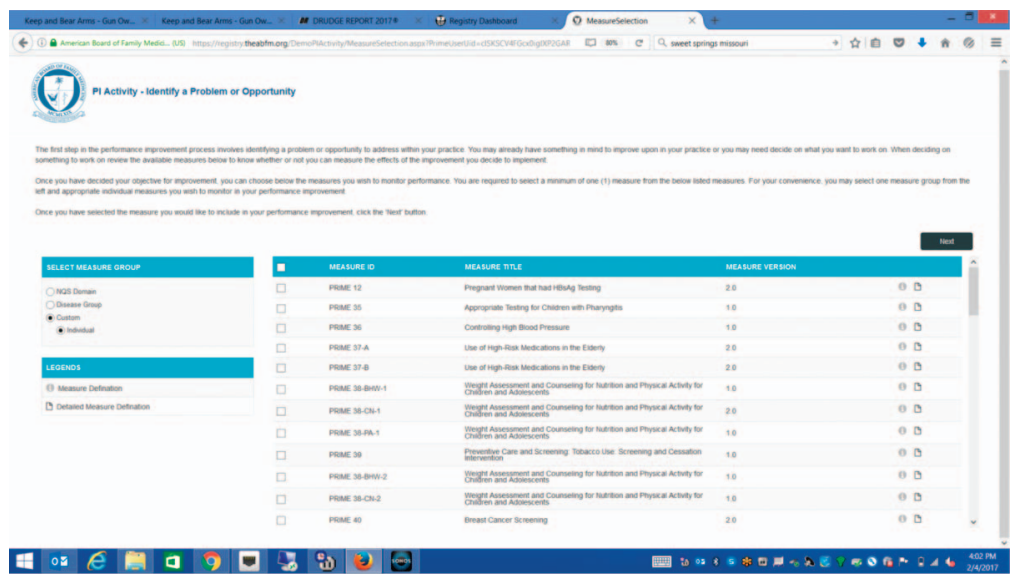

a population health assessment tool (PHAsT) that will mate with the PIA platform. ${ }^{7}$ This functionality will facilitate Diplomates' ability to assess social determinants of health among their patient populations and how these parameters affect their quality improvement efforts. At the time of this writing, we do not have access to screenshots of the PHAsT display, as the system remains in development.

The ABFM developed and deployed PPMs as a basic "baby step" to introduce Diplomates to quality improvement concepts and methods. We anticipated that family physicians and their organizations would develop increasing knowledge of and facility with quality improvement methodology over the years, and that the PIA platform could likewise evolve to support these more sophisticated efforts. The ABFM anticipates that the new platform will indeed meet this expectation!
To see this article online, please go to: http://jabfm.org/content/ 30/3/396.full.

\section{References}

1. Hunter J. The history and evolution of the PDSA cycle. The W. Edwards Demmings Institute blog. May 28, 2015. Available from: https://blog.deming. org/2015/05/the-history-and-evolution-of-thepdsa-cycle/. Accessed March 8, 2017.

2. Agency for Healthcare Research and Quality. The Ambulatory Care Quality Alliance recommended starter set. May 2005. Available from: https://archive.ahrq. gov/professionals/quality-patient-safety/qualityresources/tools/ambulatory-care/starter-set.html. Accessed March 8, 2017.

3. Phillips R. Reducing burden, ensuring competence, improving quality, and enhancing professionalism: how can ABFM contribute to all? J Am Board Fam Med 2016;29:518-9.

Figure 2. Screenshot showing an example of quality improvement interventions organized by Chronic Care Model categories.

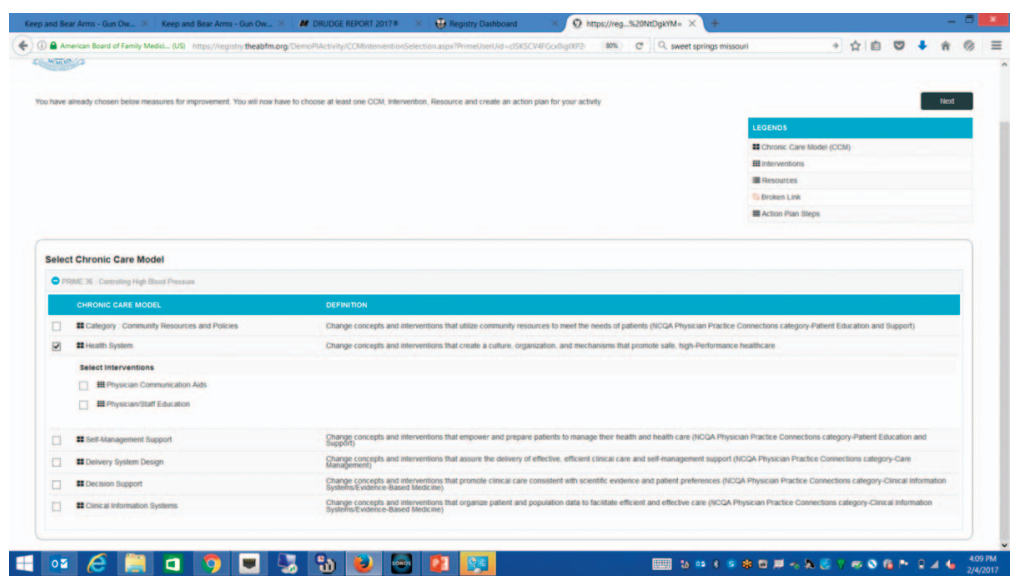


4. The Merit-Based Incentive Payment System (MIPS). 2016. Available from: https://www.cms.gov/ Medicare/Quality-Initiatives-Patient-AssessmentInstruments/Value-Based-Programs/MACRAMIPS-and-APMs/Quality-Payment-ProgramMIPS-NPRM-Slides.pdf. Accessed March 8, 2017.

5. Centers for Medicare \& Medicaid Services. Physician Quality Reporting System: measures codes. Modified February 1, 2017. Available from: https:// www.cms.gov/medicare/quality-initiatives-patient- assessment-instruments/pqrs/measurescodes.html. Accessed March 8, 2017.

6. The chronic care model. Seattle: Improving Chronic Illness Care; 2017. Available from: http:// www.improvingchroniccare.org/index.php? $\mathrm{p}=$ The_Chronic_CareModel\&s=2. Accessed March 8, 2017.

7. Puffer JC. Board news. A message from the president. J Am Board Fam Med 2017;30:266-7. 